\title{
Introducing heifers to freestall housing
}

\author{
M. A. G. von Keyserlingk, G. E. Cunha, J. A. Fregonesi, ${ }^{1}$ and D. M. Weary ${ }^{2}$ \\ Animal Welfare Program, Faculty of Land and Food Systems, University of British Columbia, 2357 Main Mall, Vancouver, \\ British Columbia, V6T 1Z4, Canada
}

\section{ABSTRACT}

Little work to date has assessed how dairy cattle respond when first introduced to freestall housing. In this study we carried out 2 experiments. The aim of experiment 1 was to assess the behavioral responses of naïve heifers to pens fitted with freestalls. Holstein heifers ( $\mathrm{n}=7$ groups, each containing 3 heifers, 3 mo of age), with no previous experience with freestalls, were initially housed on a sawdust bedded pack and fed through a fixed feed barrier for at least 6 wk and then moved to a freestall pen fitted with a head-locking feed barrier. When kept on the bedded pack, the heifers' lying time averaged $14.2 \mathrm{~h} / \mathrm{d}$. On the day heifers were moved to the freestall pen, lying times declined by 2.9 $\mathrm{h}$, but recovered on the following days. The time spent lying down on the barn floor (i.e., outside the lying area) increased by $2.5 \mathrm{~h}$ on the day heifers were introduced to freestalls and remained higher during subsequent days. Heifers spent $46 \mathrm{~min} / \mathrm{d}$ less time feeding on the day they were switched to the head-locking barrier, but recovered on the following days. In experiment 2 we assessed the behavioral responses of naïve heifers introduced to pens fitted with freestalls with or without a neck rail. Holstein heifers $(\mathrm{n}=12$ groups, each containing 2 heifers, 3 mo of age), with no previous experience with freestalls, were initially housed on a sawdust bedded pack and then moved to a freestall pen with or without neck rails. Heifers spent $4.2 \mathrm{~h} / \mathrm{d}$ less time lying down in the $24 \mathrm{~h}$ following introduction into the freestall pen; the neck rail treatment had no effect on lying time but heifers spent more time standing with just their front 2 hooves in the stall when a neck rail was in the stall. In summary, lying and feeding behavior of naïve heifers is altered following introduction to new housing.

Key words: cow comfort, lying behavior, feeding behavior, stall design

\footnotetext{
Received November 9, 2010.

Accepted December 20, 2010.

${ }^{1}$ Permanent address: Universidade Estadual de Londrina, Londrina, Parana, CEP-86051-990, Brazil.

${ }^{2}$ Corresponding author: danweary@mail.ubc.ca
}

\section{INTRODUCTION}

After weaning, farm animals are often moved to new housing. Research on how well animals adapt to such changes in housing has focused on sheep (Goddard et al., 1998), pigs (Puppe et al., 1997), and horses (Visser et al., 2008). Only one study to date has addressed this issue in dairy heifers (O'Connell et al., 1993); this study found that heifers were easier to train to freestalls when introduced at weaning versus later in life.

Growing heifers are often housed on a bedded pack before being introduced to freestalls. Freestalls are designed to provide a comfortable lying area but some aspects of stall design restrict usage. For example, cows spend less time lying and standing in the stall when partitions separating stalls are closer together (Tucker et al., 2004) and spend less time standing in the stall when the neck rail is positioned closer to the stall entrance (Tucker et al., 2005); these effects are greatest for larger cows (Fregonesi et al., 2009b). When provided a choice between freestalls and an open lying area, cows spend more time lying and standing fully in an open lying area (Fregonesi et al., 2009a).

These results suggest that cattle may have some difficulty when first introduced to freestalls. Reduced lying times can place cattle at greater risk of lameness (Singh et al., 1993, 1994). Cows may refuse to use the stalls and instead lie down in the alley, decreasing cow cleanliness and increasing the risk of intramammary infections (Breen et al., 2009). Differences in how cattle are introduced to stalls may help explain some of the variance in stall refusal; a Norwegian survey reported that stall refusal averaged $6 \%$ but ranged from 0 to $55 \%$ among dairy farms (Kjæstad and Myren, 2001a). O'Connell et al. (1992) argued that inadequate stall size and insufficient cushioning on the lying surface are also causes of stall refusal in dairy heifers.

In addition to changes in lying facilities, dairy cattle are often subject to changes in the physical environment where they access feed. Growing dairy heifers are often fed using a simple hayrack, with static bars used to separate the animal from the feed. At older ages cattle are often switched to head-locking feed barriers that facilitate restraint for breeding or health inspections. Unlike in the lying stall, animals have no option other 
than to use the device if they want to consume feed. Thus, extended refusals of the feed barrier are likely to be rare. However, Kjæstad and Myren (2001b) showed that some cattle refused to access feed from the feed barrier for a week after being moved to a new facility, suggesting that an understanding of how heifers adapt to new feeding environments is also important.

The aim of the present study was to assess how naïve dairy heifers make the transition to new housing. In experiment 1 we tested how lying behavior changes when heifers are first introduced to freestalls, and how feeding behavior is affected when heifers are first introduced to a dynamic head-locking feed barrier. In experiment 2 we tested if moving the neck-rail would increase freestall use by naïve heifers.

\section{MATERIALS AND METHODS}

\section{Animals, Experimental Pens, and Management}

All the animals were housed at The University of British Columbia Dairy Education and Research Centre (Agassiz, BC, Canada) and were managed according to the guidelines set by the Canadian Council on Animal Care (1993).

The experimental area was similar for both experiments and consisted of a bedded pack with an open lying area and 2 pens with freestalls located in a naturally ventilated, wood-frame barn. Initially, heifers were housed in the sawdust bedded pack area $(4.6 \times 5.0$ $\mathrm{m}$; width $\times$ depth) with a standing alley covered with textured rubber $(9.2 \times 3.05 \mathrm{~m})$ that divided the bedded pack from the feeding area. The feed barrier was fixed (i.e., no moving parts), with slanted bars $25 \mathrm{~cm}$ center to center and angled at $60^{\circ}$ from horizontal. All heifers had at least $8 \mathrm{wk}$ of previous experience lying on the bedded pack and had no previous experience with freestalls. The 2 adjacent freestall pens measured $7.0 \mathrm{~m}$ wide by $10.0 \mathrm{~m}$ long and contained 13 sawdust-filled stalls (arranged in 3 rows; 2 sets of 4 plus 5 at the back of the pen) measuring $0.82 \mathrm{~m}$ center to center and $1.80 \mathrm{~m}$ long. A 1.0-m-wide crossover alley allowed access from the feed alley to the back alley where the stalls were located. All pens were scraped 6 times per day. All floor surfaces in the 3 pens were covered in textured rubber. All lying areas were cleaned once per day at $0900 \mathrm{~h}$. Fresh sawdust bedding was added weekly throughout the experiment. Animals were provided fresh water from a self-filling water trough that was accessible from the feed alley.

Fresh feed was provided daily at $0800 \mathrm{~h}$; feed was pushed up at 1500 and $2200 \mathrm{~h}$. Heifers were provided ad libitum access to fescue grass hay and $2.3 \mathrm{~kg} /$ heifer per day of concentrate (textured calf grower) top-dressed onto the hay. Composition of the concentrate was $91 \%$ DM, 16.48\% CP, 23.85\% NDF, 9.04\% ADF, $1.21 \% \mathrm{Ca}$, and $0.64 \% \mathrm{P}$; the grass hay contained $90.80 \% \mathrm{DM}$, $15.14 \%$ CP, $51.71 \%$ NDF, $29.90 \%$ ADF, $0.41 \%$ Ca, and $0.28 \%$ P. Orts were removed daily immediately before feeding at $0800 \mathrm{~h}$. A mineral salt lick was available to each pen and water was freely available from a selffilling trough.

\section{Experiment 1}

In experiment 1 we tested how lying and feeding behavior changed when heifers were introduced to freestalls and to head-locking feeding barriers. Twentyone Holstein heifers were divided into 7 groups of 3 , balanced (mean $\pm \mathrm{SD})$ for age $(159 \pm 25.0 \mathrm{~d})$ and $\mathrm{BW}$ $(207 \pm 26.3 \mathrm{~kg})$. Animals were video recorded $24 \mathrm{~h} / \mathrm{d}$ for $15 \mathrm{~d}$ using 2 cameras/pen (Panasonic WV-BP334 24V, Panasonic, Mississauga, Ontario, Canada) positioned $10 \mathrm{~m}$ above the pen. The cameras were attached to a video multiplexer (Panasonic WJ FS416) and timelapse recorder (Panasonic AG 6540). Red lights (100 W) were hung $10 \mathrm{~m}$ above the pen to facilitate video recording at night. Heifers were photographed before the trial to facilitate individual identification during video playback.

During the initial $5 \mathrm{~d}$, heifers were kept on the bedded pack (baseline period). At $0800 \mathrm{~h}$ on $\mathrm{d} 6$, the animals were moved to a pen fitted with the same type of feed barrier but with freestalls rather than a pack, where they were recorded for another $5 \mathrm{~d}$ (introduction to freestall period). Freestalls were fitted with a neck-rail positioned at $1.20 \mathrm{~m}$ from the curb and $0.85 \mathrm{~m}$ from the center of bedding floor to the bottom of the rail. During these first 2 periods, heifers accessed feed via the fixed, diagonally slanted feeding barrier containing 13 feeding spaces, $25 \mathrm{~cm}$ center to center. At $0800 \mathrm{~h}$ on d 11, heifers were moved to a pen with identical freestalls but fitted with a head-locking feeding barrier $(4.6 \mathrm{~m}$ long containing 13 feeding places, $35 \mathrm{~cm}$ in center-to-center width); video recording continued for $5 \mathrm{~d}$ (introduction to head-locking barrier period).

Lying, standing, and feeding behaviors were measured from video during the final $2 \mathrm{~d}$ of the baseline period, the entire $5 \mathrm{~d}$ after introduction to freestall housing, and the first $3 \mathrm{~d}$ after introduction to headlocking barrier period. Video recordings were scanned at 5-min intervals, scoring lying, standing with all 4 hooves in the bedded area, standing with just 2 hooves in the bedded area, standing in the alley, and feeding. Latency to first lie down in a stall was recorded after introduction to freestalls.

Data were averaged by group $(n=7)$, and the effect of day tested using Proc Mixed in SAS (version 9.2; 
SAS Institute Inc., Cary, NC) with an auto-regressive (1) co-variance structure and day specified as random effect. First we tested the effect of changing from the pack to freestalls, using one specified contrast to compare the last $2 \mathrm{~d}$ in the baseline period with the day heifers were introduced to the freestalls, and a second contrast to compare the baseline days with the $2 \mathrm{~d}$ after the switch (to test if animals returned to baseline). We tested the effect of feed barrier by contrasting the last $2 \mathrm{~d}$ of the introduction to freestall period with the day heifers were introduced to head-lock feed barriers, and again used a second contrast to compared the baseline with the $2 \mathrm{~d}$ after the switch (to test if animals returned to baseline). No inferential statistics are presented for the variables standing with 2 hooves in the bedded area and lying in the alley, because heifers were not recorded performing these behaviors before the switch to freestall housing.

\section{Experiment 2}

This experiment tested how one common design feature of freestalls, the neck rail, affects stall use by naïve heifers. Twenty-four Holstein heifers were assigned to 12 pairs. Heifers averaged $162 \pm 26.4 \mathrm{~d}$ of age, $210 \pm$ $28.9 \mathrm{~kg}$ of BW, $107.5 \pm 3.76 \mathrm{~cm}$ wither height, $29.6 \pm$ $2.96 \mathrm{~cm}$ body width, and $96.3 \pm 7.15 \mathrm{~cm}$ body length

Behavior was monitored for $12 \mathrm{~d}$. Pairs were observed for $6 \mathrm{~d}$ in a pen with a bedded pack (as described above; baseline period). At $0800 \mathrm{~h}$ on $\mathrm{d} 7$, the pair was moved to a freestall pen and monitored for $3 \mathrm{~d}$ (pre-switch period). Pairs were randomly assigned to 1 of 2 starting treatments: stalls with neck rails (positioned $1.30 \mathrm{~m}$ from the curb and $0.85 \mathrm{~m}$ from the center of bedding floor to the bottom of the rail) or no neck rail. The new freestall pens were identical to those in experiment 1 but the cross-over alley located in the middle of the pen was blocked, allowing animals to access only the first row of stalls. Freestall pens were fitted with the head-locking feeding barrier described for experiment 1. Lying and standing behaviors were monitored using scan sampling (as described above) for the final $2 \mathrm{~d}$ during the baseline period, the day of the switch, and $2 \mathrm{~d}$ after the switch to freestall housing. Feeding behavior was not recorded, as we had no predictions for this measure. Latency to first lie down in a stall was recorded after the switch to freestall housing.

Data were averaged by pair $(\mathrm{n}=12)$. We first tested the effect of neck rail treatment during the $3 \mathrm{~d}$ immediately after the switch to freestall housing. The neck rail treatment was tested as a fixed effect, and the effect of day tested as a random effect using an auto-regressive (1) co-variance structure. Neck rail was significant for only one response variable (standing with the front 2 hooves in the stall), so we proceeded to compare behaviors before and after the switch to freestall housing as described for experiment 1 (i.e., not including an effect of the neck rail treatment).

\section{RESULTS}

\section{Experiment 1}

Transition from the Pack to Freestall Housing. During the baseline period, when heifers were housed on the bedded pack, lying times averaged $14.2 \mathrm{~h} / \mathrm{d}$ (Figure $1)$. On the day animals were moved to the freestall pen, lying times decreased to $11.3\left(\mathrm{~F}_{1,24}=31.4, P<0.001\right)$, but then recovered to $13.6 \mathrm{~h}$ the following days and did not differ from the baseline values. Heifers differed in their latency to first lie down in the freestalls (Figure 2 ); one heifer lay down just 25 min after introduction into the new pen, but another was never observed lying in a freestall for the duration of the study (i.e., for $8 \mathrm{~d}$ after introduction to freestall housing).

Before introduction to the freestalls, heifers were not observed lying down in the alley. This behavior spiked on the day animals were introduced to freestall housing, averaging approximately $2.5 \pm 0.50 \mathrm{~h}$ on this day and then declined to approximately $1.5 \pm 0.50 \mathrm{~h} / \mathrm{d}$ on the days following the change in housing.

While housed on the pack, heifers spent $2.2 \mathrm{~h} / \mathrm{d}$ standing idle (i.e., standing but not eating) in the alley. On the day heifers were switched to freestall housing this standing time increased to $4.7 \mathrm{~h} / \mathrm{d}\left(\mathrm{F}_{1,24}=65.0, P\right.$ $<0.001)$. Time spent standing in the alley declined to $3.1 \mathrm{~h} / \mathrm{d}$ during the days following the switch to freestalls, but was still higher than in the baseline period $\left(\mathrm{F}_{1,24}=8.6, P=0.007\right)$.

In addition to standing outside of the stalls, heifers spent some time standing fully on the bedded area. During the baseline observations on the pack, heifers spent $68 \mathrm{~min} / \mathrm{d}$ standing with all 4 hooves on the bedded area, but this declined to just $11 \mathrm{~min} / \mathrm{d}$ on the day of switch $\left(\mathrm{F}_{1,24}=45.5, P<0.001\right)$ and to $6 \mathrm{~min} / \mathrm{d}$ on the days following the switch to freestall housing $\left(\mathrm{F}_{1,24}\right.$ $=69.0, P<0.001)$. Heifers were not observed standing with just their front hooves on the pack during the baseline period. On the day heifers were introduced to freestall housing, they spent on average $71 \mathrm{~min} / \mathrm{d}$ standing with their front hooves in the stall and their rear hooves in the alley. This time decreased to $36 \mathrm{~min} / \mathrm{d}$ on the days following the switch to freestall housing.

On average, heifers spent approximately $6 \mathrm{~h} / \mathrm{d}$ at the feed bunk before and after the switch to freestall housing. This behavior did not change on the day of switch or on the days following the switch to freestall housing. 


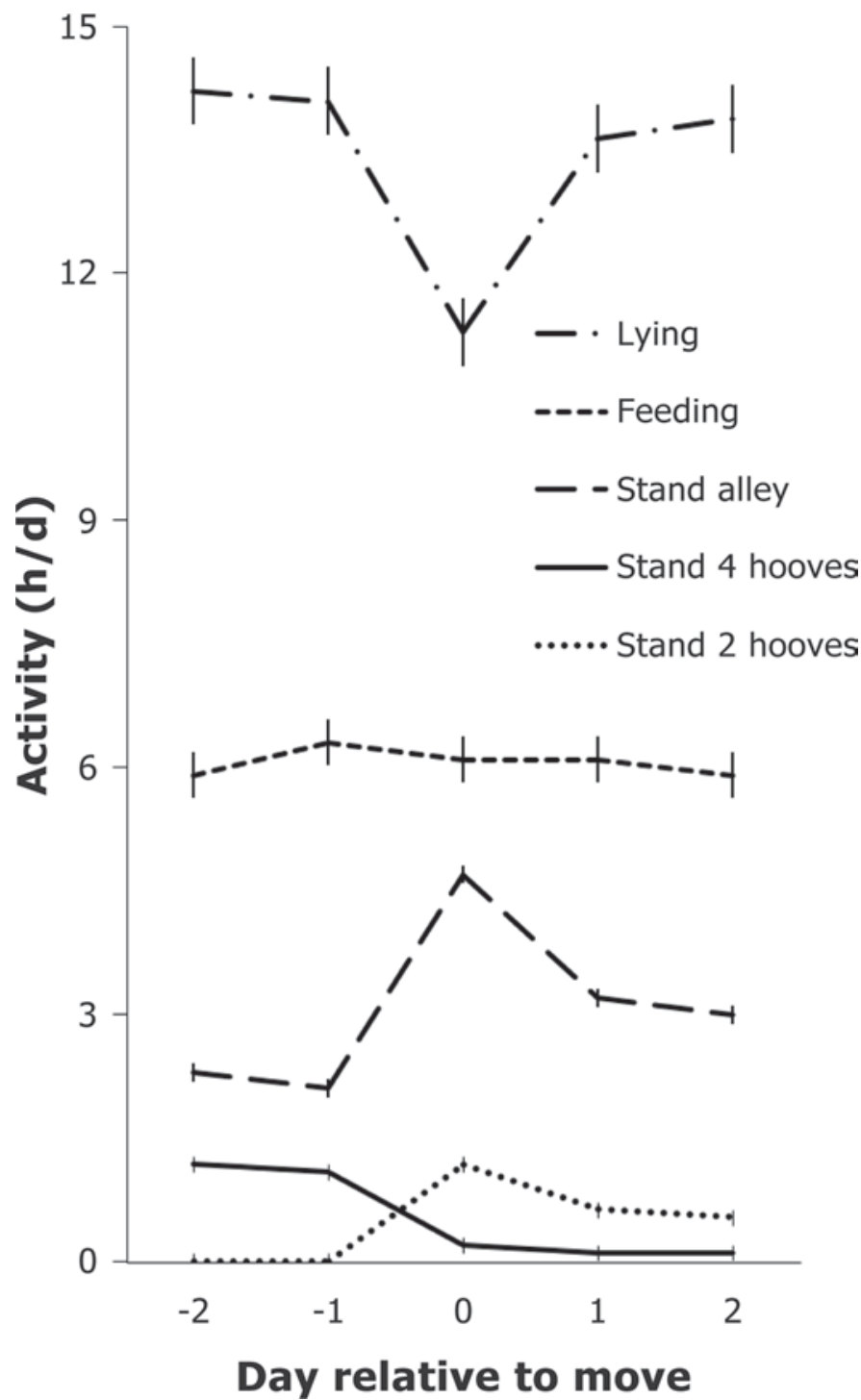

Figure 1. Least squares means $( \pm \mathrm{SE})$ for experiment 1. Groups of heifers ( $\mathrm{n}=7$, each of 3 animals) were first housed on a bedded pack (d -2 to -1$)$ and then moved to a pen with freestalls (d 0 to 2 ). Times (h/d) are shown separately for lying on the bedded area (pack or freestall surface), feeding, standing in the alley (not feeding), and standing with either 2 hooves or 4 hooves in the bedded area.

Transition from Fixed to Head-Locking Feed Barriers. No differences were observed in the time spent lying down in the freestalls, standing in the alley, or standing either partially or fully in the freestalls when the heifers accessed feed via a fixed barrier versus when they were switched to a head-locking feed barrier (Table 1). Only one animal was observed lying in the alley during this phase of the experiment, so no statistics are provided for this variable.

The time heifers spent feeding declined from $6.1 \mathrm{~h} / \mathrm{d}$ during the last $2 \mathrm{~d}$ of feed access from the fixed barriers to $5.4 \mathrm{~h} / \mathrm{d}$ on the day they were switched to the new head-locking barriers $\left(\mathrm{F}_{1,24}=8.64, P=0.007\right)$. Feeding time recovered to $5.9 \mathrm{~h} / \mathrm{d}$ on the days following the switch and did not differ statistically from that in the baseline period.

\section{Experiment 2}

Heifers introduced to freestalls with the neck rail present spent more time standing with their front 2 hooves in the stall compared with heifers using stalls where the neck rail was absent (Table $2 ; \mathrm{F}_{1,10}=15.26$, $P=0.003)$; treatment did not affect any other behavior and no day by neck rail interactions were observed.

The heifers spent $15.0 \mathrm{~h} / \mathrm{d}$ lying down when housed on the pack, but lying time decreased to $10.7 \mathrm{~h} / \mathrm{d}$ on the day animals were first moved to a freestall pen $\left(\mathrm{F}_{1,40}\right.$ $=51.3, P<0.001 ;$ Figure 3). Lying times increased to $13.2 \mathrm{~h} / \mathrm{d}$ on the following days but were still lower than baseline values $\left(\mathrm{F}_{1,40}=6.4, P<0.02\right)$.

Some animals (38\%) spent time lying down in the alley (averaging $33.0 \pm 16.8 \mathrm{~min} / \mathrm{d}$ ). In this experiment some animals $(42 \%)$ were also recorded lying backwards in the stall $(39.0 \pm 21.6 \mathrm{~min} / \mathrm{d})$. Lying down in the alley declined to approximately $2.5 \pm 2.4 \mathrm{~min} / \mathrm{d}$ on the days following the change in housing; lying down backwards in the stall increased to $42.0 \pm 18.3 \mathrm{~min} / \mathrm{d}$ during the same period.

As in experiment 1, heifers varied considerably in their latency to first lie down in the freestalls. Latencies were somewhat shorter than in experiment 1 , but 9 of the 24 heifers took more than $4 \mathrm{~h}$ to first use a freestall after the introduction to the new pen.

While housed on the pack, heifers spent $7.6 \mathrm{~h} / \mathrm{d}$ standing in the alley (standing idle or eating). On the day heifers were switched to freestall housing this standing time increased to $10.4 \mathrm{~h} / \mathrm{d}\left(\mathrm{F}_{1,40}=56.7, P<0.001\right)$. Time spent standing in the alley declined to approximately $9.0 \mathrm{~h} / \mathrm{d}$ during the days following the switch, a

Table 1. Mean \pm SE time (h/d) heifers spent lying in the freestalls, standing in the alley, standing with their front hooves in the stall, or with 4 hooves in the stall, and time spent feeding in experiment 1 when access to feed was via a fixed feed barrier $(\mathrm{d}-2$ and -1 before the switch) versus head-lock feed barrier (d 0, 1, and 2 after the switch)

\begin{tabular}{|c|c|c|c|}
\hline \multirow[b]{2}{*}{ Activity } & \multicolumn{3}{|c|}{ Day relative to switch in feed barrier } \\
\hline & -2 and -1 & 0 & 1 and 2 \\
\hline $\begin{array}{l}\text { Lying in the stall } \\
\text { Standing }\end{array}$ & $13.8 \pm 0.3$ & $13.9 \pm 0.3$ & $14.2 \pm 0.3$ \\
\hline Alley (idle) ${ }^{1}$ & $3.0 \pm 0.3$ & $3.4 \pm 0.3$ & $3.0 \pm 0.3$ \\
\hline Two hooves in stall & $0.6 \pm 0.1$ & $0.7 \pm 0.1$ & $0.6 \pm 0.1$ \\
\hline Four hooves in stall & $0.8 \pm 0.1$ & $1.0 \pm 0.1$ & $0.7 \pm 0.1$ \\
\hline Feeding & $6.1 \pm 0.3$ & $5.4 \pm 0.3$ & $5.9 \pm 0.3$ \\
\hline
\end{tabular}

${ }^{1}$ Standing idle in the alley (not feeding). 
value still higher than the baseline period $\left(\mathrm{F}_{1,40}=16.6\right.$, $P<0.001)$.

In addition to standing in the alley, heifers also stood fully on the bedded area. During the baseline observations on the pack, heifers spent approximately 1.5 h/d standing with all 4 hooves on the bedded area. In contrast, heifers reduced the amount of time spent standing with all 4 hooves in the stall to $1 \mathrm{~h} / \mathrm{d}$ on the day of switch $\left(\mathrm{F}_{1,40}=11.9, P<0.002\right)$ and declined further to $0.5 \mathrm{~h} / \mathrm{d}$ on the days following the switch to freestall housing $\left(\mathrm{F}_{1,40}=42.2, P<0.001\right)$.

The heifers were not observed standing with just their front hooves on the pack during the baseline period. On the day heifers were introduced to freestall housing, they spent on average $36 \mathrm{~min} / \mathrm{d}$ standing with their front hooves in the stall and their rear hooves in the alley. This time decreased to approximately $25 \mathrm{~min} / \mathrm{d}$ on the days following the switch to the new housing.

\section{DISCUSSION}

Freestalls are designed with the specific intention of providing a comfortable place for dairy cattle to lie down while encouraging defecation and urination in the alley outside of the stall. In both experiments, lying times declined when heifers were first introduced to freestalls. To our knowledge, our study is the first to show this effect. Heifers reduced their lying time by 40 to $50 \%$ when moved from the sawdust pack to freestalls, suggesting that they were not able to adapt immediately to the new conditions. The smaller lying area of the freestall compared with that available on the bedded pack may have made it more difficult for heifers to lie down (Færevik et al., 2008). Previous work has shown that dairy cattle require considerable lunge space when
Table 2. Mean \pm SE time (h/d) heifers spent lying in the freestall, standing in the alley, and standing with either their front hooves in the stall or with 4 hooves in the stall, in experiment 2 for the first $3 \mathrm{~d}$ after the switch to freestall housing; results are shown separately for pairs introduced to stalls where the neck rail was either absent or present

\begin{tabular}{lcc}
\hline & \multicolumn{2}{c}{ Neck rail } \\
\cline { 2 - 3 } Activity & Absent & Present \\
\hline Lying in stall & $11.8 \pm 0.6$ & $12.4 \pm 0.6$ \\
Standing & & \\
Alley & & \\
Two hooves in stall & $9.6 \pm 0.3$ & $9.7 \pm 0.3$ \\
Four hooves in stall & $0.3 \pm 0.1$ & $0.7 \pm 0.1$ \\
\hline
\end{tabular}

${ }^{1}$ Standing outside the bedded area (includes feeding).

transitioning from standing to lying positions (Ceballos et al., 2004), and heifers may have found it difficult to perform these movements when presented with the freestall for the first time.

Some heifers were able to adapt to freestalls more quickly than others, as evidenced by the large variation in the latency to use the stalls for the first time. Although the majority of heifers used the stalls within the first $4 \mathrm{~h}$, some individuals experienced very long latencies. These long latencies are a concern; cattle are highly motivated to spend time lying down (Jensen et al., 2004), and this motivation to lie down increases after just a few hours of deprivation (Metz, 1985).

Lying times recovered in the days following introduction into the freestalls, and seemed to recover more quickly in the present study than in the study by Jensen (1999) on tethered heifers in a stall with concrete flooring. The stall size used in our study was smaller than that used by Jensen (1999), but the deep sawdust bedding provides a softer surface and likely encouraged longer lying times. Mature dairy cattle show a strong

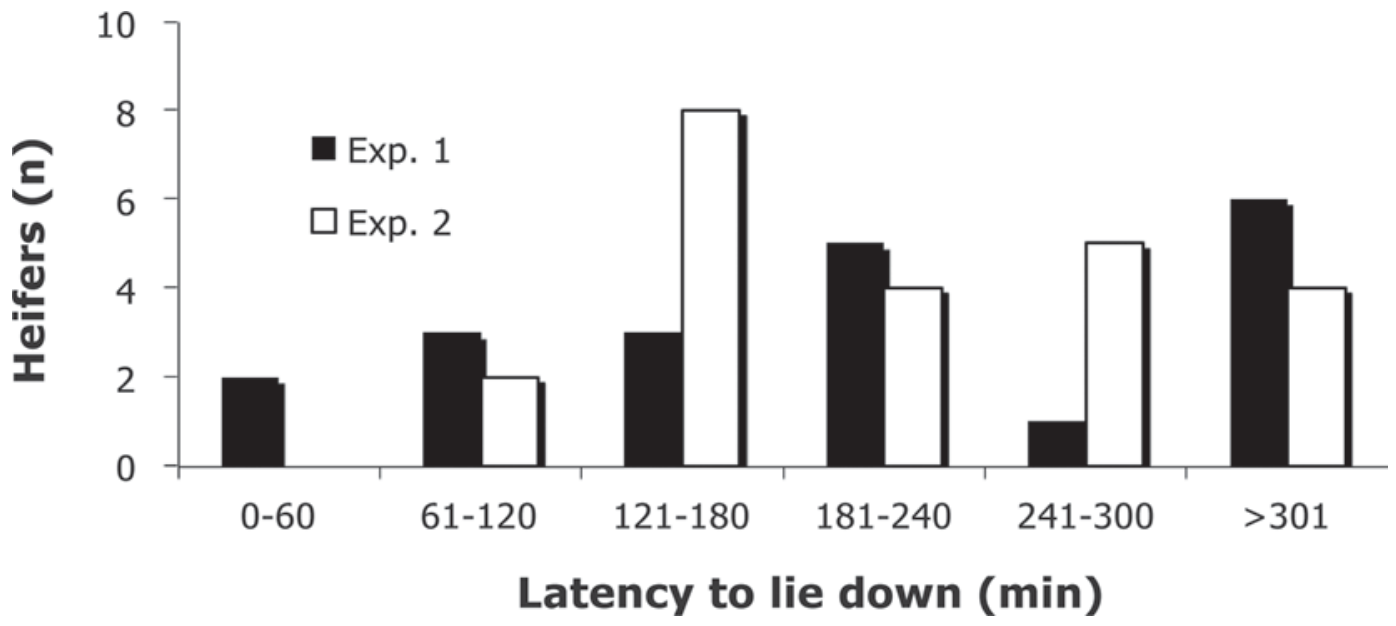

Figure 2. Frequency distribution of latency $(\mathrm{min})$ to first lie down in a freestall after introduction to freestall housing. Latencies are shown separately for heifers in experiments $1(\mathrm{n}=21)$ and $2(\mathrm{n}=24)$. 
preference for lying down on softer surfaces (Tucker et al., 2003) and lie down longer in stalls with more bedding (Tucker and Weary, 2004; Tucker et al., 2009).

In the current study, undesirable lying behaviors such as stall refusal and lying backwards in the stalls were greatest on the first day heifers were introduced to freestall housing. This result corresponds with previous research showing that stall refusal is highest during the first few days after a new animal is moved into a herd (Kjæstad and Myren, 2001b). In our study, stall refusal was specific to the introduction to freestalls; group composition was not changed when animals were moved, and we saw no change in lying behavior when heifers were moved to a new pen with a different feed barrier but identical stalls. Heifers that show persistent stall refusal are at increased risk for culling (Kjæstad and Simensen, 2001), and we encourage future work to examine factors that reduce stall refusal.

Dairy cattle may also have difficulty learning to use different lying areas if the bedding surface is less attractive to them; for example, they avoid wet bedding materials (Fregonesi et al., 2007). Freestalls provide not only a place to lie down but also a place to stand away from the concrete alley. Dairy cattle also spend approximately 35 to $175 \mathrm{~min} / \mathrm{d}$ standing on bedding in loose housing systems (Fregonesi and Leaver, 2001; Stefanowska et al., 2001). Time spent standing fully or partially in the stall is affected by many factors in adult cattle, such as neck rail placement and stall size (Tucker and Weary, 2004; Tucker et al., 2005). Standing in the stall may also be a way of avoiding uncomfortable standing surfaces outside of the stall (Stefanowska et al., 2001) or as a refuge from dominant herd mates (Galindo and Broom, 2000). Heifers spent more time standing with all 4 hooves on the bedded surface of the sawdust pack compared with the freestall; previous work on adult dairy cattle showed a similar preference for standing on an open bedded area (Fregonesi et al., 2009a). The reduction in lying time was accompanied by an increase in time spent standing in the alley and time spent standing with 2 hooves in the freestall when the heifers were moved to the freestall. This increase in time spent standing with 2 hooves in the stall was greatest on the first day following introduction into the new housing environment.

The neck rail is normally positioned with the aim of preventing cows from defecating in the stall, decreasing the risk of soiling the stall surface with feces and urine and helping to keep cows clean. More restrictive placements (i.e., when the rail is closer to the stall entrance and stall surface) prevent animals from standing with all 4 hooves in the stall (Tucker et al., 2005). As in previous work on adult cattle (Bernardi et al., 2009; Fregonesi et al., 2009b), we found that the neck rail increased time spent standing partially in the stall and had little effect on lying time. Some risk of injury exists from the neck rail (Veissier et al., 2004) and we had expected that this stall feature to be more detrimental to stall usage. Future work should consider other stall attributes to improve the transition to new housing systems.

The use of a head-locking feed barrier in freestalls is common as it allows the animals to be restrained

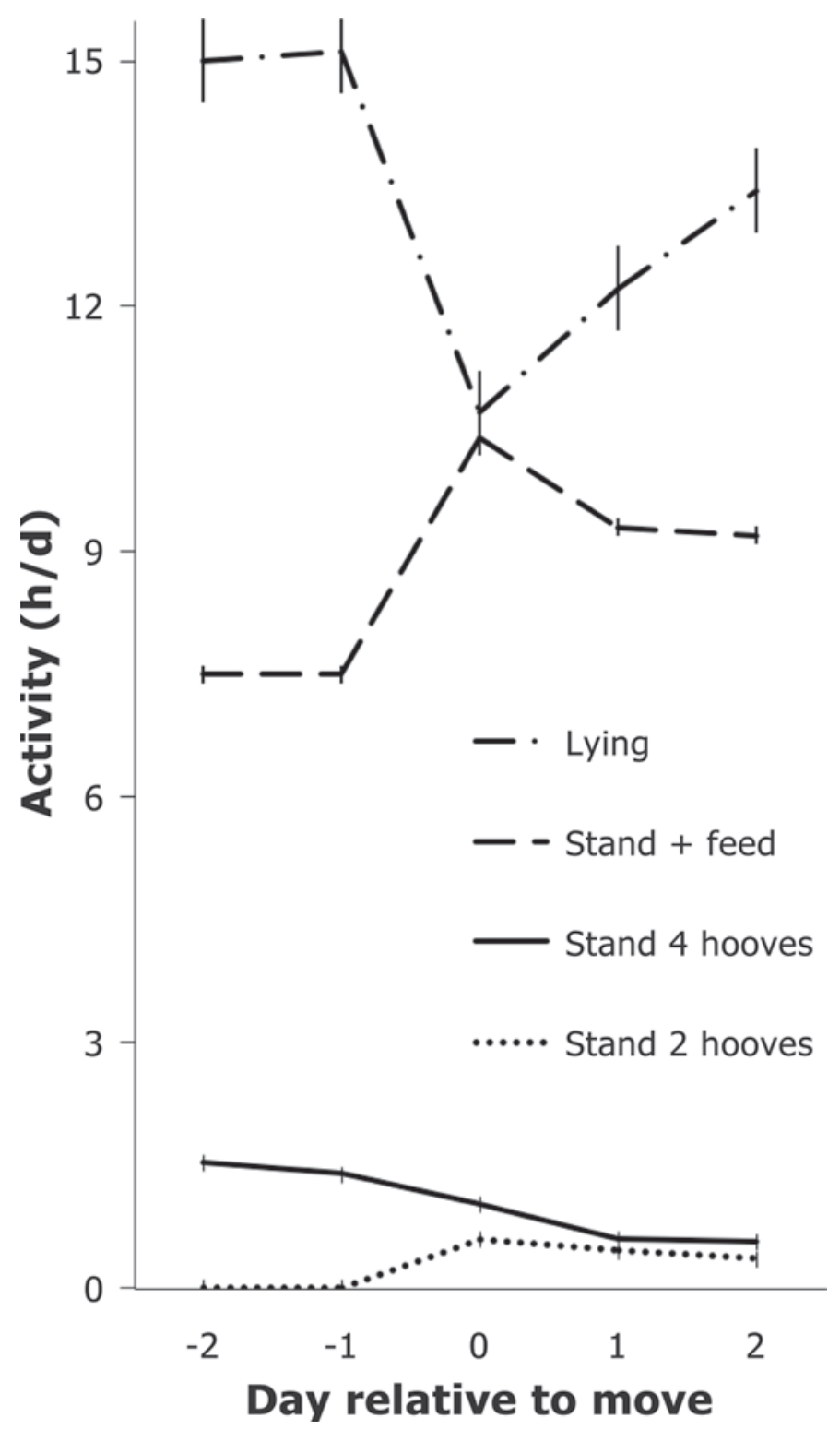

Figure 3. Least squares means $( \pm \mathrm{SE})$ for experiment 2. Pairs of heifers ( $\mathrm{n}=12$ pairs) were first housed on a bedded pack ( $\mathrm{d}-2$ to -1 before switch) and then moved to a pen with freestalls ( $\mathrm{d} 0$ to 2 after the switch). Times (h/d) are shown separately for lying on the bedded area (pack or freestall surface), standing outside the bedded area (including time feeding), and standing with either 2 hooves or 4 hooves in the bedded area. 
for breeding and herd health checks. This type of feed barrier has been recommended for adult dairy cows as it reduces competition during feeding (Huzzey et al., 2006), particularly for subordinate animals. We observed a decrease in feeding time on the day heifers were switched to the head-lock barrier, indicating some difficulties in learning how to use this device, but animals returned to baseline feeding times in the days following the switch. Heifers had no other choice of where to access feed. In contrast, when provided a new lying area heifers could still lie down in the feed alley or the cross-over alley. Other studies have reported that refusal to access the feeding area is less frequent than stall refusal (Kjæstad and Myren, 2001b).

In conclusion, dairy heifers changed their lying and standing behaviors when introduced to freestalls and changed their feeding behavior when introduced to head-locking feed barriers. Most changes were transitory and behavior returned to baseline the following day. However, some heifers continued to show undesirable lying behavior, including lying in the alley, for several days after the introduction to freestall housing.

\section{ACKNOWLEDGMENTS}

We thank the faculty, staff, and students at University of British Columbia's Dairy Education and Research Centre and the University's Animal Welfare Program. The Animal Welfare Program is funded by Canada's Natural Sciences and Engineering Research Council (Ottawa, ON, Canada) Industrial Research Chair Program with industry contributions from the Dairy Farmers of Canada (Ottawa, ON, Canada), Westgen Endowment Fund (Milner, BC, Canada), Pfizer Animal Health (Kirkland, QC, Canada), BC Cattle Industry Development Fund (Kamloops, BC, Canada), the BC Milk Producers (Burnaby, BC, Canada), BC Dairy Foundation (Burnaby, BC, Canada), BC Dairy Education and Research Association (Abbotsford, BC, Canada), and Alberta Milk (Edmonton, AB, Canada). J. A. F. also thanks Universidade Estadual de Londrina-UEL and Coordenação de Pessoal de Nivel Superior-CAPES.

\section{REFERENCES}

Bernardi, F., J. A. Fregonesi, C. Winckler, D. M. Veira, M. A. G. von Keyserlingk, and D. M. Weary. 2009. The stall-design paradox: Neck rails increase lameness but improve udder and stall hygiene. J. Dairy Sci. 92:3074-3080.

Breen, J. E., M. J. Green, and A. J. Bradley. 2009. Quarter and cow risk factors associated with the occurrence of clinical mastitis in dairy cows in the United Kingdom. J. Dairy Sci. 92:2551-2561.

Canadian Council on Animal Care. 1993. Guide to the Care and Use of Experimental Animals. Vol. 1. E. D. Olfert, B. M. Cross, and A. A. McWilliam, ed. CCAC, Ottawa, Canada.

Ceballos, A., D. Sanderson, J. Rushen, and D. M. Weary. 2004. Improving stall design: Use of 3-D kinematics to measure space use by dairy cows when lying down. J. Dairy Sci. 87:2042-2050.
Færevik, G., K. Jentland, S. Løvik, I. L. Andersen, and K. E. Bøe 2008. Resting pattern and social behaviour of dairy calves housed in pens with different sized lying areas. Appl. Anim. Behav. Sci. 114:54-64.

Fregonesi, J. A., and J. D. Leaver. 2001. Behaviour, performance and health indicators of welfare for dairy cows housed in strawyard or cubicle systems. Livest. Prod. Sci. 68:205-216.

Fregonesi, J. A., D. M. Veira, M. A. G. von Keyserlingk, and D. M. Weary. 2007. Effects of bedding quality on lying behavior of dairy cows. J. Dairy Sci. 90:5468-5472.

Fregonesi, J. A., M. A. G. von Keyserlingk, C. B. Tucker, D. M. Veira and D. M. Weary. 2009b. Neck-rail position in the free stall affects standing behavior and udder and stall cleanliness. J. Dairy Sci. 92:1979-1985

Fregonesi, J. A., M. A. G. von Keyserlingk, and D. M. Weary. 2009a. Cow preference and usage of free stalls compared with an open pack area. J. Dairy Sci. 92:5497-5502.

Galindo, F., and D. M. Broom. 2000. The relationships between social behavior of dairy cows and the occurrence of lameness in three herds. Res. Vet. Sci. 69:75-79.

Goddard, P. J., A. R. Fawcett, and A. J. Macdonald. 1998. The adaptation of hill lambs to housing conditions. Appl. Anim. Behav. Sci. 58:331-339.

Huzzey, J. M., T. J. DeVries, D. M. Weary, and M. A. G. von Keyserlingk. 2006. Stocking density and feed barrier design affect the feeding and social behavior of dairy cattle. J. Dairy Sci. 89:126133.

Jensen, M. B. 1999. Adaptation to tethering in yearling dairy heifers assessed by the use of lying down behavior. Appl. Anim. Behav. Sci. $62: 115-123$.

Jensen, M. B., L. Munksgaard, L. J. Pedersen, J. Ladewig, and L. Matthews. 2004. Prior deprivation and reward duration affect the demand function for rest in dairy heifers. Appl. Anim. Behav. Sci. $88: 1-11$.

Kjæstad, H. P., and H. J. Myren. 2001a. Cubicle refusal in Norwegian dairy herds. Acta Vet. Scand. 42:181-187.

Kjæstad, H. P., and H. J. Myren. 2001b. Failure to use cubicles and concentrate dispenser by heifers after transfer from rearing accommodation to milking herd. Acta Vet. Scand. 42:171-180.

Kjæstad, H. P., and E. Simensen. 2001. Cubicle refusal and rearing accommodation as possible mastitis risk factors in cubicle-housed dairy heifers. Acta Vet. Scand. 42:123-130.

Metz, J. H. M. 1985. The reaction of cows to a short-term deprivation of lying. Appl. Anim. Behav. Sci. 13:301-307.

O'Connell, J. M., P. S. Giller, and W. J. Meaney. 1992. Factors affecting cubicle utilization by dairy cattle using stall frame and bedding manipulation experiments. Appl. Anim. Behav. Sci. 35:11-21.

O'Connell, J. M., P. S. Giller, and W. J. Meaney. 1993. Weanling training and cubicle usage as heifers. Appl. Anim. Behav. Sci. $37: 185-195$.

Puppe, B., M. Tuchscherer, and A. Tuchscherer. 1997. The effect of housing conditions and social environment immediately after weaning on the agonistic behaviour, neutrophil/lymphocyte ratio and plasma glucose level in pigs. Livest. Prod. Sci. 48:157-164.

Singh, S. S., W. R. Ward, J. W. Huges, K. Lautenbach, and R. D. Murray. 1994. Behaviour of dairy cows in a straw yard in relation to lameness. Vet. Rec. 135:251-253.

Singh, S. S., W. R. Ward, K. Lautenbach, J. W. Huges, and R. D. Murray. 1993. Behaviour of first lactation and adult dairy cows while housed and at pasture and its relationship with sole lesions. Vet. Rec. 133:469-474.

Stefanowska, J., D. Swierstra, C. R. Braam, and M. M. W. B. Hendriks. 2001. Cow behaviour on a new grooved floor in comparison with slatted floor, taking claw health and floor properties into account. Appl. Anim. Behav. Sci. 71:87-103.

Tucker, C. B., and D. M. Weary. 2004. Bedding on geotextile mattresses: How much is needed to improve cow comfort? J. Dairy Sci. 87:2889-2895.

Tucker, C. B., D. M. Weary, and D. Fraser. 2003. Effects of three types of free-stall surfaces on preferences and stall usage by dairy cows. J. Dairy Sci. 86:521-529. 
Tucker, C. B., D. M. Weary, and D. Fraser. 2004. Free-stall dimensions: Effects on preference and stall usage. J. Dairy Sci. 87:12081216.

Tucker, C. B., D. M. Weary, and D. Fraser. 2005. Influence of neck-rail placement on free-stall preference, use, and cleanliness. J. Dairy Sci. 88:2730-2737.

Tucker, C. B., D. M. Weary, M. A. G. von Keyserlingk, and K. A. Beauchemin. 2009. Cow comfort in tie-stalls: Increased depth of shavings or straw bedding increases lying time. J. Dairy Sci. 92:2684-2690.

Veissier, I., J. Capdeville, and E. Delval. 2004. Cubicle housing systems for cattle: Comfort of dairy cows depends on cubicle adjustment. J. Anim. Sci. 82:3321-3337.

Visser, E. K., A. D. Ellis, and C. G. van Reenen. 2008. The effect of two different housing conditions on the welfare of young horses stabled for the first time. Appl. Anim. Behav. Sci. 114:521-533. 